\title{
A Responsabilidade Civil no Código do Japão, comparado com o do Brasil *
}

\author{
R. Limongi França \\ Membro da Academia Brasileira de Letras Jurídicas. \\ Professor Honorário da Univ. de S. Marcos de Lima. \\ Professor de Direitó Civil da USP.
}

\section{Introducāo:}

1. Gênese histórica de ambos os Códigos.

1. Ubicação de ambos os códigos no conspecto geral do Direito Comparado.

3. Afinidades genéricas dos dois ordenamentos.

4. Reflexos dessa afinidade no campo da Responsabilidade Civil.

II. Posicãa Sistemática e divisão da matéxia:

1. Posição Sistemática.

2. Sistema interno e divisão da matéria.

III. Principio Geral da responsabilidade:

1. Princípio básico.

2. Extensão ao dano moral.

IV. Responsabilidade em razão de fato do sujeito:

1. Responsabilidade do menor.

2. Responsabilidade do alienado mental.

3. Responsabilidade por morte.

4. Outras responsabilidades por crime.

V. Responsabilidade em razão de fato de outrem:

1. Dano causado por incapaz.

2. Dano causado pelo empregado.

3. Dano causado pelo hóspede.

4. Dano causado por terceiro, em geral.

VI. Responsabilidade em razão de fato de coisa:

1. Dano causado por coisa animada.

2. Dano causado por defeito de construcão.

3. Dano causado por coisas lançadas ou caídas

VII. Regras complementares dal Responsabilidade:

1. Pluralidade da responsabilidade.

2. Dano ao nascituro.

3. Estado de necessidade.

4. Liquidação do dano.

5. Prescrição.

(*) Dedico este trabalho aos eminentes colegas do Japão, Prof. Dr. Koshiso Fuji, da Universidade de Tokio e Sussumu Ito, Diretor da Biblioteca da Suprema Corte do Japão, bem assim aos nisseis Desembargador Kasuo Watanabe e Doutor Mario Ninomiya. 


\section{Introdução:}

1. Gênese histórica de ambos os Códigos.

A crescente importância do Japão no Mundo Moderno, especialmente a partir de meados do século passado, culminou com uma série de providências de caráter cultural e jurídico, das quais resultou a idéia de uma ampla codificação, cujo fulcro central foi sem dúvida a da elaboração de um Código Civil, à semelhança de uma considerável parte das nações ocidentais.

Para tanto, a Coroa Japonesa encarregou do projeto o jurista francês Gustave Boissonde de Fontarabie, em 1879, do que resultou a promulgação do ordenamento em 1890 (v. W. J. Sebald, "The Civil Code of Japan», London, 1934).

Entretanto, o excessivo estrangeirismo da obra, calcada quase inteiramente nos textos do Código de Napoleão, tornou-a inexeqüível, de onde a oposição de respeitável plêiade de juristas japoneses.

Daí resultou um novo Código, cujos primeiros três livros - Parte Geral, Coisas e Obrigações — foram sancionados em 1896.

Os dois subseqüentes - Família e Sucessões - vieram a lume em 1898, de tal modo que o ordenamento, por inteiro, passou a vigorar a partir de 16 de julho desse ano.

Fácil é notar naqueles três iniciais a acentuada influência do Código Alemão, cujo projeto terminara em junho de 1895 e fora transmitido ao Reichstag em 27 de janeiro de 1896 (v. Raoul de la Grasserie, «Code Civil Alemand», Introduction, Paris, 1897).

No entanto, a parte concernente à família e. às sucessões «is primarily a codification of native Japanese customs» (Sebald, op. cit.).

Ao seu turno, o Código do Brasil adveio primacialmente da Consolidação das Leis Civis, de Teixeira de Freitas, de 1858, elaborada sobre as Ordenações do Reino de Portugal de 1602, cujas raízes datam das primeiras leis reais dos monarcas lusitanos, a partir do século XII, bem assim dos inúmeros diplomas que se lhe seguiram, quer em Portugal, quer no Brasil, a partir de sua independência em 1822.

Após a Consolidação, houve vários projetos - o primeiro do próprio Teixeira de Freitas, depois o de Nabuco de Araújo, o de Felício dos Santos, e o de Coelho Rodrigues - até culminarem no de Clóvis Bevilaqua, de 1899, o qual se tornou lei em 1916, para vigorar a partir de $1^{\text {o }}$ de janeiro de 1917.

Se em todos eles houve influência multiforme por parte dos códigos ocidentais, especialmente o francês e o de Zürich, no último, que veio a entrar em vigor até os nossos dias, a presença mais constante, a par das tradições luso-brasileiras, é, semelhantemente ao que se deu no Japão, a do ordenamento germânico. 
2. Ubicação de ambos os Códigos no conspecto geral do Direito Comparado.

Em nosso «Manual de Direito Civil» (vol. I, págs. 98-104, 4a ed., RT, 1980) dividimos os sistemas de Direito Comparado em abertos, como o Canônico, o Israelita, o Muçulmano, e circunscritos.

Estes últimos, que se caracterizam pelo fato de, diversamente daqueles, se conterem dentro dos limites de um ou mais Estados, em virtude de sua adoção oficial por parte destes, se subdividem em: I. Sistemá Romano; II. Sistema do Common Law; e III. Sistemas Orientais.

Fácil, à face da sinopse, localizar o Código do Japão entre os últimos, do mesmo modo que o do Brasil entre os primeiros, dado que, a despeito das tradições luso-brasileiras, de natureza específica, este país tem toda a sua formação jurídica, assim como dos seus ancestrais, fundada na sabedoria dos jurisconsultos do Império Romano. (Cf. René David, «Traité Élémentaire de Droit Civil Comparé», Paris, 1950; Pierre Arminjon, Boris Nolde e Martin Wolf, «Traité de Droit Civil Comparẻ», 3 vols.).

3. Afinidades genéricas dos dois ordenamentos.

A despeito da distância que os separa, posto que são países antípodas, os respectivos códigos civis apresentam inegáveis afinidades.

Primeiramente, a elaboração de cada qual teve início efetivo entre o terceiro e o último quartel do século XIX.

Por outro lado, um e outro mantiveram, no referente à Família e às Sucessões, os elementos básicos oriundos das tradições nacionais. Por exemplo, no Brasil, como regra, o casamento em comunhão de bens, só revogado pela recente Lei do Divórcio, de 1977 (v. R. Limongi França, "A Lei do Divórcio, Comentada e Documentada», São Paulo, Saraiva, 1978); do mesmo modo, no Japão, toda a particular estrutura da sociedade doméstica (Código Civil do Japão, arts. 725 e segs.).

Mas no que tange à regulamentação, pode dizer-se que os códigos dos dois países sofreram influência, inicialmente do Código Napoleão e depois do Código Germânico, conforme as diferentes etapas dos respectivos trabalhos preparatórios.

4. Reflexos dessa afinidade no campo da Responsabilidade Civil.

Bem nítidos são os reflexos da afinidade entre os Códigos do Brasil e do Japão, no que tange especialmente à matéria da Responsabilidade Civil.

A sede do assunto no Código Francês são os arts. 1.382 a 1.386, capítulo que leva a rubrica - «Des délits et des quasi-délits», enquanto no BGB, são os parágrafos 823 a 853, sob o título - «Unarlaubte Handlungen», cuja tradução é — «Atos ilícitos». 
O ordenamento francês, com cinco artigos sobre a matéria, é mais conciso; o germânico, com trinta e um, por força, é mais pormenorizado. Por outro lado, não se pode negar a própria influência daquele sobre este, além do que, ambos, haurem suas luzes fundamentais, no que tange ao assunto, no Direito Romano, através dos respectivos cultores, como Pothier na França e Savigny na Alemanha.

Assim, as fontes básicas, no que concerne ao tema, quer do Código Japonês, quer do Brasileiro, são, em última análise, as próprias fontes romanisticas, filtradas por certa dose de influências tradicionais.

Mas, a despeito do contingente francês na técnica da elaboração legislativa, tanto o Código do Brasil como o do Japão, um e outro acentuadamente desenvolvidos na disposição da matéria, mais se aproximam do ordenamento alemão do que do napoleônico.

Se há semelhanças, também incidem diferenças. E é disso que trataremos a seguir.

\section{Posição sistemática e divisão da matéria:}

1. Posição sistemática.

Para que tenhamos melhor noção comparativista de como se resolveu o problema da posição sistemática da matéria, nos códigos japonês e brasileiro, é de bom aviso referenciá-los ao francês e ao germânico, dada a qualidade destes de códigos-tipos. livros:

Assim, relembramos que o Código Napoleão se divide em três

I. Pessoas.

II. Dos bens e das diferentes modificações da propriedade.

III. Das diferentes maneiras pelas quais se adquire a propriedade.

Neste ordenamento, o assunto em apreço concerne ao Título IV, do Livro III, sob a rubrica — «Das obrigações que se formam sem convenção».

Ao seu turno o Código Alemão se compõe de cinco livros:

I. Parte geral.

II. Direito das obrigações.

III. Direito das coisas.

IV. Direito de família.

V Direito das sucessões.

Os «Atos ilícitos» aí são regulados no Livro II, Seção sétima «Das obrigações em particular», Título vigésimo quinto, o último da seção mencionada. 
O Código do Japão, à semelhança do germânico, a despeito da diferença da ordem, também é composto de cinco livros:

I. Parte geral.

II. Direitos reais.

III. Obrigações.

IV. Sucessão.

Semelhante, dedica aos «Atos ilícitos», o último capitulo (n. V) do Livro das Obrigações.

Por sua vez, ainda aqui, aproximam-se os códigos germânico, japonês e brasileiro.

Com efeito o Código do Brasil, em virtude de tradições próprias que se firmaram na «Consolidação Teixeira de Freitas», de 1858, se antecipou de cerca de quatro décadas ao sistema do Código Alemão, quanto à divisão da matéria em Parte Geral e Parte Especial, do que, aliás, como é sabido, tomaram conhecimento os seus elaboradores, pois, entre outros elementos, a consolidação brasileira já estava traduzida por Raoul de la Grasserie na década de 1890 (v. «Lois Civiles du Brésil», Paris, 1897).

Destas duas partes, a especial é dividida em quatro livros:

I. Do direito de família.

II. Do direito das coisas.

III. Do direito das obrigações.

IV. Do direito das sucessões.

O princípio geral da responsabilidade civil se encontra na «Parte Geral», art. 159, mas a regulamentação da matéria se vê no sétimo e oitavo dos nove títulos do livro das Obrigações, sob as rubricas «Das obrigações por atos ilícitos» e «Da liquidação das obrigações».

2. Sistema interno e divisão da matéria.

Tanto o Código do Brasil, como o do Japão, não apresentam um sistema interno da matéria, como se dá, por exemplo, com o Código das Obrigações do Líbano, no qual a preclara assessoria de Josserand possibilitou esse importantíssimo progresso técnico (cf. Elie J. Boustany, «Code des Obligations et des Contrats», Beyrouth, 1956).

Não obstante, ambos mostram uma razoável seqüência lógica, sobretudo tendo-se em conta a época em que foram promulgados.

Mas força é convir que, diante dos novos avanços do assunto, essa seqüência resulta insuficiente, de onde procurarmos enquadrá-la numa divisão científica, que, entre outros, pode ter como esboço o seguinte: 
A) Princípio Geral da Rosponsabilidade.

B) Responsabilidade, em razão de fato do sujeito.

C) Responsabilidade, em razão de fato de outrem.

D) Responsabilidade, em razão de fato de coisa.

E) Regras Complementares da Responsabilidade.

Em nosso estudo comparativo seguiremos a ordem acima proposta.

\section{Princípio geral da responsabilidade:}

1. Princípio básico.

À semelhança do Código Francês (arts. 1.382 e 1.383) e do Alemão ( $\$$ 823), o do Japão exara o princípio geral da matéria, logo ao início do capítulo sobre o ato ilícito.

É o que se encontra nos arts. 709 e 710, nestes termos:

Artigo 709. Uma pessoa que viola intencionalmente ou negligentemente o direito de outrem está obrigado a fazer a compensação do prejuízo daí resultante.

Artigo \%10. Uma pessoa que está obrigada a prejuízos, de acordo com as determinações do Artigo precedente, deve fazer compensação por isso, igualmente com respeito a um prejuízo não pecuniário, não importando, em um e outro caso, se a injúria foi contra a pessoa, liberdade ou reputação de outrem, ou contra os seus direitos de propriedade.

A tradução oficial, em inglês, patrocinada pelo Ministério da Justiça daquele país, com efeito, apresenta este texto:

Article 709. A person who violates intentionally or negligently the right of another is bound to make compensation for damagelarising therefrom.

Article 710. A person who is liable in damages in accordance with the provisions of the preceding Article must make compensation therefor even in repect of a non-pecuniary damage, irrespective of whether such injury was to the person, liberty or reputation of another or to his property rights.

O Código Brasileiro adota método diferente.

O longo desenvolvimento de sua Parte Geral, fruto de arraigada tradição que advém do trabalho pioneiro de Teixeira de Freitas (v. «Consolidação», de 1858; e «Esboço», de 1860-1872) levou o legislador a consagrar aí o princípio geral básico da responsabilidade civil, o que assim está disposto no art. 159:

«Aquele que, por ação ou omissão voluntária, negligência ou imprudência, violar direito, ou causar prejuízo a outrem, fica obrigado a reparar o dano». 
A matéria é completada, ainda na Parte Geral, pelos arts. 79 e 80, que rezam deste modo:

«Se a coisa perecer por fato alheio à vontade do dono, terá este ação, pelos prejuízos, contra o culpado».

«A mesma ação de perdas e danos terá o dono contra aquele que, incumbido de conservar a coisa, por negligência a deixe perecer; cabendo a este, por sua vez, direito regressivo contra o terceiro».

A complementação não pára aí. Na própria Parte Especial, Livro das Obrigações, Título «Das Obrigações por atos ilícitos», determina ainda 0 art. 1.518 , pr.:

«Os bens do responsável pela ofensa ou violação do direito de outrem ficam sujeitos à reparação do dano causado ....».

Como se vê, o Código do Japão é mais conciso e mais técnico, notando-se aí a presença direta do ordenamento alemão que assim reza:

$\ll \S 823$. Quem dolosa ou culposamente lesiona de forma antijurídica a vida, o corpo, a saúde, a liberdade, a propriedade ou qualquer outro direito de outra pessoa, está obrigado com ela à indenização do dano causado por isto».

O texto original, na eđição de Karl Larenz é este:

$\S$ 823. (Schuldhafte Verletzung ausschlieBlicher Rechte) Wer vorsätzlich oder fahrlässig das Leben, den Körper, die Gesundireit die Freiheit, das Eigentum oder cin sonstiges Recht eines anderen widerrechtlich verletzt, ist dem anderen zum Ersatze des daraus entsichenden Schadens verpflichtet.

Não obstante, a substância da disposição é a mesma, afirmação esta que, à altura presente do desenvolvimento da doutrina e da jurisprudência brasileira, é igualmente válida para o que, de modo genérico, respeita à extensão do dano indenizável.

E o que veremos a seguir.

2. Extensão ao dano moral.

A extensão da indenização de prejuízos, em caso de dano moral, é bastante clara no Código do Japão, conforme se vê no próprio art. 710 onde se fala em «compensation there for even in respect of a non-pecuniary damage».

Logo a seguir, no art. 711, a respeito de reparação por morte, se declara que a mesma tem lugar «even in cases where no property right... has been violated».

No Código Brasileiro, a consagração não é tão evidente, de modo que muitos autores, como Agostinho Alvim, sustentaram a inexistên- 
cia de regra ampla da reparação do dano moral (v. «Da Inexecução das Obrigações e suas Conseqüências», $4^{\mathrm{a}}$ ed., Saraiva, 1972).

Não obstante, o próprio autor do Projeto de Código Civil Brasileiro, Clóvis Bevilaqua, já defendia tese contrária, baseada no art. 76 v. «Código Civil Comentado», vol. I, p. 337, $7^{\text {a }}$ ed., 1944).

Esse preceito reza o seguinte:

«Para propor, ou contestar uma ação, é necessário ter legítimo interesse, econômico ou MORAL».

De nossa parte, sustentamos tese semelhante no concernente à indenização de dano moral quanto às lesões ao nome civil e aos direitos da personalidade em geral (v. R. Limongi França, «Do Nome Civil das Pessoas Naturais», 1" edição, 1958; cf. 3 $3^{a}$ ed., 1975; «Manual de Direito Civil», vol. I, $1^{\text {a }}$ ed., 1965; cf. $4^{\text {a }}$ ed., 1980; artigo da Revista dos Tribunais, vol. 567, 1983 - «Direitos da Personalidade - Coordenadas Fundamentais»).

Atualmente, a Doutrina Brasileira é praticamente unânime em reconhecer essa orientação (v. Wilson Mello da Silva, «O Dano Moral e sua Reparação», Rio, 1955; Alcino de Paula Salazar, "Reparação do Dano Moral», Rio, s/d; Ávio Brasil, «O Dano Moral no Direito Brasileiro», Rio, 1944, e muitos outros).

Em nosso repertório de jurisprudência sobre responsabilidade civil ao longo de cento e trinta julgados, deparamos oito sobre a matéria, em meio aos quais pode afirmar-se que, não obstante os avanços do Direito Científico, os nossos Tribunais ainda se vêem hesitantes sobre 0 assunto.

Há acórdãos consagradores, há outros que concedem parcialmente e há aqueles que o denegam (v. R. Limongi França, "Jurisprudência da Responsabilidade Civil», SP, RT, 1981, 347 págs.; v. págs. 35-66).

\section{Responsabilidade em razão de fato do sujeito:}

1. Responsabilidade do menor.

Artigo \%12. Se, nos casos em que um menor causou prejúzo a outrem, ele não estava na posse de suficiente inteligência para entender sua responsabilidade em relação ao ato, o mesmo não estará obrigado pelos prejuízos com respeito a esse ato.

$\mathrm{Na}$ edição oficial em inglês, o preceito assim está redigido:

Article 712. If, in cases where a minor has caused demage to another, he was not in possession of sufficient intelligence to understand his responsibility for the act, he shall not be liable in damages in respect of such act. 
No Brasil não há norma semelhante.

A matéria, porém, pode ser resolvida à luz das regras da Parte Geral, concernentes à incapacidade do menor, a qual é absoluta até 16 anos, e relativa dos 16 aos 21, quando adquire a maioridade.

Entretanto, a irresponsabilidade do menor não elide a responsabilidade dos seus pais e tutores pelos danos por ele causados, o que constitui matéria de responsabilidade por fato de outrem, a qual será tratada a seu tempo.

\section{Responsabilidade do alienado mental.}

Sobre a responsabilidade do alienado mental, o Código do Japão apresenta disposições bastante explícitas, conforme se vê em seu artigo 713, nestes termos:

Artigo 713. Uma pessoa que, durante estado de comprometimento mental, causou prejuízos a outrem, não está obrigado a eles; mas isto não se aplica, se ela provocou em si mesma um comprometimento mental temporário, tanto intencionalmente, como pela própria negligência.

$\mathrm{Na}$ versão inglesa:

Article 713. A person who, while in a state of mental unsoundness, has caused damage to another is not liable in damages; but this shall not apply, if he has brought upon himself a temporary mental unsoundness either intentionally or by his own negligence.

Mas, no Brasil, tal como com relação à responsabilidade do menor, não há uma regra sintética dessa natureza.

Ainda aqui, de modo semelhante, a questão se soluciona de acordo com normas da Parte Geral, cujo artigo 5", n. II declara absolutamente incapazes «os loucos de todo o gênero».

Com relação a estes, em muitos casos, coloca-se a questão da responsabilidade durante os chamados «lucida intervala» (v. R. Limongi Franç, «Absolutamente Incapazes», in «Enciclopédia Saraiva do Direito», SP, 1977-1982).

Quanto à alienação transitória, provocada, o encaminhamento da matéria se estriba no princípio geral do dolo e da culpa, conforme os arts. 159 e 1.518 do Código.

\section{Responsabilidade por injúria.}

Expressivo mandamento encontramos no Código do Japão sobre a responsabilidade por injúria. 
Está assim formulado no art. 723:

Artigo 723. Se uma pessoa injuriou a reputação de outra, a Corte pode na aplicação da lei quanto a esta última expedir ordem determinando ao autor providencie as medidas necessárias para a restauração da reputação desta, quer em lugar dos pagamentos dos prejuízos, quer juntamente com estes.

$\mathrm{Na}$ tradução oficial para o inglês:

Article 723. If a person has injured the reputation of another, the Court may on the application of the latter make an order requiring the former to take suitable measures for the restoration of the latter's reputation either in lieu of or together with damages.

Portanto, como se vê, aí se alinham três esquemas de sanções:

A) Providências para a restauração da reputação do injuriado.

B) Indenização dos prejuízos.

C) Aplicação alternativa ou cumulativa das duas sanções acima, conforme o arbítrio do Tribunal.

O preceito correspondente do Código Brasileiro é o artigo 1.547, que não alude à restauração do bom nome do injuriado.

Fala apenas na «reparação do dano» e, no parágrafo único, para a hipótese de impossibilidade de prova do prejuízo, o pagamento do «dobro da multa no grau máximo da pena criminal respectiva».

Como as multas criminais brasileiras sofrem esvaziamento constante em virtude da inflação monetária, essa parte do dispositivo resulta de certo modo inócuo, quanto ao aspecto da indenização dos prejuizos.

Entretanto, em se tratando de injúria através da imprensa, o art. 29 da Lei 5.250, de 9 de fevereiro de 1967, assegura ao ofendido não só o direito de resposta, como ainda o de retificação (v. Antonio Costella, «Direito da Comunicação», SP, RT, 1976; Celso Delmanto, «Código Penal Anotado», 4a ed., SP, Saraiva, 1983).

4. Responsabilidade por morte.

Sobre a responsabilidade por morte, é a seguinte o preceito japo. nês:

Artigo 711. Uma pessoa que causou a morte de outra está obrigada aos prejuízos, em relação aos pais, o cônjuge, e os filhos do morto, mesmo nos casos em que nenhum direito patrimonial dos mesmos tenha sido violado. 
$\mathrm{Na}$ versão inglesa:

Article 711. A person who has caused the death of another is liable in damages to the parents, the sponse and the children of the deceased, even in cases where no property right of theirs has been violated.

Ressalte-se a expressão alusão aos prejuízos não patrimoniais.

O preceito brasileiro é aparentemente mais restrito, determinando, no art. 1.537, que a indenização, no caso de homicídio, consiste:

I. No pagamento das despesas com o tratamento da vítima, seu funeral e o luto da familia.

II. Na prestação de alimentos às pessoas a quem o defunto os devia.

A feição do artigo é taxativa, dando a impressão de que desses parâmetros não se pode afastar o aplicador da lei.

Entretanto, conforme já se depara em alguns julgados dos nossos Tribunais, a reparação por dano moral em caso de morte vai ganhando acesso.

Um dos mais expressivos é o que se pronunciou no caso Francisco Moreira da Silva X Rede Ferroviária Federal, cujo relator foi o então Juiz de Alçada Severo da Costa, hoje Desembargador do Tribunal de Justiça do Rio de Janeiro e Membro da Academia Brasileira de Letras Jurídicas.

O dano moral foi reclamado pelo pai da vítima e, em meio à ementa do acórdão, é de se ressaltar este belo ensinamento:

«Todo e qualquer dano causado a alguém, ou ao seu patrimônio, deve ser indenizado, de tal obrigação não se excluindo o mais importante deles, que é o dano moral, que deve autonomamente ser levado em conta.

O dinheiro possui valor permutativo, podendo-se, de alguma forma, lenir a dor com a perda de um ente querido, pela indenização, que representa também punição e desestímulo do ato ilícito». (In R. Limongi França, «Jurisprudência da Responsabilidade Civil», p. 35, SP, ed. RT, 1981).

\section{Outras responsabilidades por crime.}

No Código Japonês não encontramos a previsão expressa de indenização por danos causados em virtude de crime, além do que respeita ao homicídio e à injúria.

Diferentemente, o Código Brasileiro é abundante e minucioso em outras prescrições dessa natureza. 
Fugindo ao modelo tanto francês como alemão, além dos dois delitos acima mencionados, no capítulo «Da Liquidação das Obrigações resultantes de Atos Ilícitos», se prevêem ainda os crimes de «ferimento ou outra ofensa à saúde» (art. 1.538) ; de «usurpação ou esbulho do alheio»; de «ofensa à honra da mulher» (art. 1548); de «violência sexual, ou ultraje ao pudor» (art. 1.549); de lesão à «liberdade pessoal».

Em cada qual dessas espécies se consideram nuances e graduações, de acordo com a gravidade da violência e a extensão do prejuízo, arrematando o art. 1.553 que «nos casos não previstos... se fixará por arbitramento a indenização».

A despeito da ausência de normas análogas no Código do Japão, parece-nos evidente que os respectivos princípios gerais são de molde a suprir as lacunas, na medida da necessidade jurídica.

\section{Responsabilidade em razão de fato de outrem:}

\section{Dano causado por incapaz.}

O dano causado por incapaz, provavelmente o aspecto mais importante e complexo da assim chamada responsabilidade indireta, é objeto, no Código do Japão, de minucioso mandamento, conforme as duas partes do art. 714, que assim dispõe:

Artigo \%14. Uma pessoa que está no dever legal de supervisionar alguém sob incapacidade, está obrigada, nos casos em que o incapaz não é responsável, de acordo com os dois artigos precedentes, a fazer compensação por qualquer prejuízo que a pessoa sob a incapacidade tenha causado a uma terceira pessoa; mas isto não se aplicará, se a pessoa que está no dever de supervisão não negligenciou o seu dever. Uma pessoa que tem supervisão sobre uma pessoa sob incapacidade, em lugar da pessoa que está na obrigação de supervisionar, também assumirá a responsabilidade mencionada no parágrafo precedente.

Confira-se com a versão inglesa:

Article 714. A person who is under a legal duty to supervise a person under disability is bound, in cases where the latter is not responsible in accordance with the preceding two Articles, to make compensation for any damage which the person under disability has caused to a third person; but this shall not apply, if the person who is under a duty of supervision has not neglected his duty.

A person who has supervision over a person under disability in place of the person who is under a duty to supervise also shall assume the responsibility mentioned in the preceding paragraph. 
O início da primeira parte, o preceito, como se vê, estabelece o princípio básico da responsabilidade pelo dano causado pelo incapaz, por parte da pessoa que está no dever legal de o supervisionar.

O final da mesma primeira parte isenta o supervisor na hipótese de ausência de culpa.

Já na segunda e última parte prevê os casos de exercício da supervisão por parte de outrem, que não seja pessoa via de regra obrigada a isso.

Corresponderia, no Direito Brasileiro, às espécies de guarda, judicial ou não, ou, ainda, te simples pessoas encarregadas de cuidar, de tomar conta do incapaz.

Essas pessoas, determina o preceito, são igualmente responsáveis.

O Código do Brasil utiliza-se de outra técnica.

No art. 1.521, §§ I e II, assim preceitua:

«São também responsáveis pela reparag̣ão civil:

I - Os pais, pelos filhos menores que estiverem sob seu poder e em sua companhia.

II - O tutor e o curador, pelos pupilos e curatelados que se acharem nas mesmas condições».

Ressaltem-se aí os requisitos do poder e da companhia, em um outro caso.

Nos artigos subseqüentes, o 1.522 e 1.523 , respectivamente, se acrescenta o requisito da «culpa, ou negligência», bem assim a previsão de que, se o incapaz causador do dano não for descendente do que respondeu, este poderá reaver daquele aquilo que foi obrigado a pagar.

No caso Roberto de Namede Costa Leite X a menor C.A.G., filha de desquitados, o Tribunal de Justiça de São Paulo decidiu pela irresponsabilidade do pai, ante desastre automobilístico provocado pela ré, em virtude de a mesma se encontrar sob a guarda da mãe. (V $\mathbf{R}$. Limongi França, «Jurisprudência da Responsabilidade Civil», p. 11-13).

Num outro feito, em que foram partes Edson Medeiros X Antonio Paschoal da Silva, e o dano foi o de vazamento de olho causado por menor, o mesmo Tribunal foi bastante drástico decidindo que -

«Consumado um ilícito por um incapaz, dele AUTOMATICAMENTE DEFLUI PRESUNÇÃO DE CULPA IN VIGILANDO, de seus responsáveis legais».

Mas acrescentou:

«Tão só não responderão estes por indenização, caso cumprida e convincentemente patenteiem que se não houveram com a menor falha» (op. cit., págs. 13-15). 
2. Dano causado pelo empregado.

A hipótese do dano infligido pelo empregado de uma pessoa, ou assemelhado, está pormenorizadamente prevista nos artigos 715 e 716 do Código do Japão.

Seus termos são os que seguem:

Artigo 715. Uma pessoa que emprega outra para levar avante um empreendimento está obrigada a fazer compensação por prejuízos causados a uma terceira pessoa pelo empregado, no curso da execução do empreendimento; mas isto não se aplicará, se o empregador exerceu o devido cuidado na contratação do empregado e na supervisão do empreendimento, ou se o prejuízo se tivesse verificado mesmo se o devido cuidado houvesse sido exercido.

Uma pessoa que supervisiona o empreendimento em lugar do empregador assumirá também a responsabilidade mencionada no parágrafo precedente.

As determinações dos dois parágrafos precedentes não impedirá o empregador nem o supervisor de demandar por reembolso o empregado.

Artigo 716. A pessoa que transmitir a ordem para um trabalho não está obrigada a fazer compensação por qualquer prejuízo causado a uma terceira pessoa pelo contratante no curso deste trabalho; entretanto, isto não se aplicará, se a pessoa que transmitir a ordem cometeu falta com respeito à ordem ou suas instruções.

$\mathrm{Na}$ versão oficial em inglês:

Article 715. A person who employs another to carry out an undertaking is bound to make compensation for damage done to a third person by the employee in the course of the execution of the undertaking; but this shall not apply, if the employer has exercised due care in the appointment of the employe and the supervision of the undertaking or if the damage would have ensued even if due care had been exercised.

A person who supervises the undertaking in place of the employer shall also assume the responsibility mentioned in the preceding paragraph.

The provisions of the preceding two paragraphs shall not preclude the employer not the supervisor from demanding reimbursement from the employee.

Article 716. The person who placed the order for a work is not bound to make compensation for any damage caused 
to a third person by the contractor in the course of such work; however, this shall not apply if the person who placed the order was in fault in regard to the order or his instructions.

A regra geral da matéria encontra-se no início da primeira parte do art. 715, onde se estabelece, em suma, que, em princípio,o empregador responde pelos prejuízos causados por seus empregados, evidentemente no exercício do empreendimento.

No final desta primeira parte se prevêem dois casos da irresponsabilidade:

A) Se o empregador exerceu o devido cuidado na contratação do empregado e na supervisão do empreendimento.

B) Se o prejuizo se houvesse verificado mesmo se os cuidados necessários tivessem sido tomados.

Essas duas espécies de irresponsabilidade são de ausência de culpa, cuja prova há de incumbir ao empregador.

A segunda parte estende as mesmas regras ao supervisor, isto é, à pessoa contratada pelo empregador, para supervisionar o serviço do empregado.

Daí parece poder concluir-se que, havendo supervisor, este responderia antes do empregador.

$\mathrm{Da}$ letra do preceito pode mesmo depreender-se que a presença do supervisor exclui a responsabilidade do empregador, entendimento que, em termos de comparação, seria difícil de se sustentar no Direito Brasileiro, conforme as regras que adiante veremos.

A terceira parte do artigo 715 contempla a ação de regresso, tanto do empregador, como do supervisor, contra o empregado.

Por sua vez, o art. 716 estabelece diferença entre o simples transmissor da ordem de serviço e o supervisor. Diferentemente deste, a regra que concerne àquele é a da irresponsabilidade.

Mas, acrescenta o preceito, essa norma na hipótese de falta na transmissão das instruç̃̃es.

No Código Brasileiro, o assunto está regulado no art. 1.521, n. III, onde, ao lado de outras espécies, se determina que igualmente responde pela indenização -

«O patrão, amo ou comitente, por seus serviçais e prepostos, no exercício do trabalho que lhes competir, ou por ocasião dele».

$\mathrm{O}$ art. 1.523 estende à hipótese o requisito da «culpa ou negligência». 
Por outro lado, o art. 1.522 acrescenta norma relevante, qual seja a abrangência da norma em relação «às pessoas jurídicas, que exercerem exploração industrial».

No mesmo conspecto da matéria, a Constituição Brasileira, de 1969, art. 107, determina que — «as pessoas jurídicas de direito público responderão pelos danos que seus funcionários, nessa qualidade, causarem a terceiros». O respectivo parágrafo único prevê, a seguir, que - «caberá ação regressiva contra o funcionário responsável, nos casos de dolo ou culpa (v. Yussef Said Cahali, «Responsabilidade Civil do Estado», SP, RT, 1982; Mario Moacyr Porto, «Responsabilidade do Estado pelos atos dos seus Juizes», in «Revista dos Tribunais», n. 563, p. 9, SP, 1982; Afranio Lyra, «Responsabilidade Civil», Bahia, 1977).

O princípio do direito de regresso é igualmente previsto, para os particulares, no art. 1.524, desde que a pessoa por quem se indenizou não seja descendente do responsável.

\section{Dano causado pelo hóspede.}

O Código Civil Brasileiro, no art. 1.521, já citado anteriormente, no minucioso elenco de casos de responsabilidade por fato de outrem, traz importante referência ao dano causado pelo hóspede, expressão esta que usamos em sentido genérico.

$\mathrm{Na}$ verdade, o preceito é bem mais específico ao dispor no inciso IV que respondem pela indenização -

«Os donos de hotéis, hospedarias, casas ou estabelecimentos, onde se albergue por dinheiro, mesmo para fins de educação, pelos seus hóspedes, moradores e educandos».

Esse tipo de responsabilidade indireta, na qual se poderia mesmo sustentar a existência de responsabilidade objetiva, supõe a albergaria, a hospedagem mediante remuneração.

No Código do Japão, não há preceito semelhante e parece-nos difícil deduzí-lo dos seus princípios gerais.

\section{Dano causado por terceiro, em geral.}

A matéria, embora aparentemente subsidiária e complementar, na verdade pode ser objeto de toda uma monografia em apartado, pois múltiplos são os casos não apenas de danos de terceiros, como ainda de terceiros envolvidos em danos de outra espécie, como o caso daquele que não é proprietário, mas tem a custódia de um animal.

Neste item, porém, desejamos apenas ressaltar a tese básica do direito de regresso, isto é, de uma vez feita a indenização, poder aquele que a pagou recobrá-la do causador direto. 
Já vimos que esse princípio é agasalhado no art. 715 do Código do Japão no que tange ao direito do empregador e do supervisor, quanto ao dano causado pelo empregado.

A mesmo norma é seguida ainda pelo art. 717, terceira parte, no que tange à responsabilidade por dano causado por defeito de construção ou estaqueamento.

A orientação do Código Brasileiro é substancialmente a mesma, conforme o art. 1.524, o qual entretanto exclui da legitimidade passiva para a propositura da ação de regresso os descendentes daquele que pagou.

\section{Responsabilidade em razão de fato de coisa:}

1. Dano causado por coisa animada.

Trata-se em suma dos danos causados pelos animais.

A matéria é antiqüíssima e já se encontra no próprio Código de Hamurabi, § 251, datado de 2.200 a.c. (v. «O Código de Hamurabi», ed., de E. Bouzon, Petrópolis, 1976).

Também a previu a Lei Romana das XII Tábuas, de 420 a.C., cuja tâbua n. VII, § 1 assim dispõe:

Si quadrupes pauperiem faxit, dominus noxiae aestimiam offerto; si nolet, quod noxit dato.

A tradução é a seguinte:

«Se um quadrúpede causa dano, o proprietário indenize o valor do dano, ou entregue o animal ao prejudicado» (av. Daubanton, «Le Trésor de l'Ancienne Jurisprudence Romaine», Metz, 1811; Silvio Meira, «A Lei das Doze Tábuas», Rio, 1961; «Lei das XII Tábuas», in «Enciclopédia Saraiva do Direito»; R. Limongi França, «As Raízes da Responsabilidade Aquiliana», in «Revista dos Tribunais», 1983).

O Código Francês preceituou sobre o assunto no art. 1.385 e o Alemão no art. 833.

A norma do Código do Japão, sobre o assunto, é a seguinte:

Artigo 718. O possuidor de um animal deverá compensar todo prejuízo causado por este a uma outra pessoa; entretanto, isto não se aplicará, se aquele o conservou sob tal cuidado, que seja próprio em relação à espécie e natureza do animal.

A pessoa que tenha a custódia do animal em lugar do possuidor também assumirá a responsabilidade mencionada no parágrafo precedente. 
$\mathrm{Na}$ versão inglesa:

Article 718. The possessor of an animal must compensate any damage caused by it to another person; however, this shall not apply, if he has kept it with such care as is proper according to the species and nature of the animal.

A person who has the custody of an animal in place of the possessor shall also assume the responsibility mentoned in the preceding paragraph. 1.527:

O Código Brasileiro é mais pormenorizado, conforme o seu art.

«O dono, ou detentor, do animal ressarcirá o dano por este causado, se não provar:

I - Que o guardava e vigiava com cuidado preciso.

II - Que o animal foi provocado por outro.

III - Que houve imprudência do ofendido.

IV - Que o fato resultou de caso fortuito, ou força maior».

A despeito da diferença de forma, os preceitos muito se aproximam um do outro.

Entretanto, enquanto o Código Japonês declara responsáveis o «possuidor» ou «o que tem a custódia» do animal, o do Brasil refere ao «dono ou detentor».

Aqui, um e outro são responsáveis solidários. Naquele parece excluir-se o proprietário, que não esteja na posse do animal.

Não é inviável, porém, que a co-responsabilidade do proprietário. no Direito Japonês, se possa deduzir dos seus princípios gerais.

$\mathrm{O}_{\mathrm{S}}$ incisos I a IV do Direito Brasileiro se referem, em suma, à prudência do responsável, à imprudência da vítima e à força maior.

Embora de maneira bastante genérica a expressão «such care as is proper», não deixa de abranger todas essas hipóteses.

\section{Dano causado por defeito de construção.}

Também esta matéria tem raízes profundas e bem definidas nos grandes sistemas do Direito Antigo, como o Assírio-babilônico e o Romano, de onde, através do Direito Medieval, passaram, no Ocidente, para os códigos modernos.

O Código do Japão a regula no artigo 717 , do qual já cuidamos acima, a respeito de dano de terceiro.

Disposto em três partes, assim se exara:

Artigo 71\%. Se algum prejuízo foi causado a outrem, por causa de defeito na construção ou manutenção de uma 
estrutura de raiz, a pessoa que esteja na posse da estrutura estará obrigada pelos prejuízos à parte prejudicada; mas se a pessoa na posse exerceu o devido cuidado para prevenir a ocorrência de tal prejuízo, a compensação do prejuízo deverá ser feita pelo proprietário.

As determinações do parágrafo precedente se aplicarão com as necessárias modificações, nos casos em que haja defeito no assentamento ou no suporte de bambus ou de madeira. Se nos casos mencionados nos dois parágrafos precedentes existir outra pessoa que seja responsável pela perpetração do prejuízo, tanto o possuidor como o proprietário poderá exercer o direito para obter o reembolso contra essa outra pessoa.

São os seguintes os termos da versão oficial inglesa:

Article 717. If any damage has been caused to another person by reason of any defect in the construction or maintenance of a structure on land, the person in possession of the structure shall be liable in damages to the injured party; but if the person in possession has exercised due care in order to prevent the occurrence of such damage, compensation for the damage must be made by tre owner. The provisions of the preceding paragraph shall apply with necessary modifications, in cases where any defect exists in the planting or the support of bamboos or of trees.

If in the cases mentioned in the preceding two paragraphs there exists any other person who is responsible for causing the damage, either the possessor or the owner may exercise the right to obtain reimbursement against such other person.

Decompondo-se as respectivas disposições:

I - Pelo dano de edifícios responde o possuidor.

II - Se o possuidor não tem culpa, responde o proprietário.

III - Havendo defeitos de assentamento ou nos suportes de bambu, a responsabilidade de um e outro se aferirá com «necessary modifications».

IV - Em qualquer dos casos acima, havendo terceiro responsável, caberá aos que pagaram direito de reembolso.

O preceito brasileiro é bem mais simples, conforme o art. 1.528:

«O dono do edifício ou construção responde pelos danos que resultarem de sua ruína, se esta provir da falta de reparos, cuja necessidade fosse manifesta». 
A norma geral, bem se vê, é a da responsabilidade do proprietário.

Exige-se, porém, o requisito da culpa (in fine), e a ação de regresso contra terceiros responsáveis, inclusive o possuidor, se deduz dos princípios gerais.

3. Dano causado por coisas lançadas ou caídas.

O Código do Brasil, no art. 1.529, cuida dos danos causados por coisas lançadas ou caídas de um edifício, nestes termos:

«Aquele que habitar uma casa, ou parte dela, responde pelo dano proveniente das coisas que dela caírem ou forem lançada em lugar indevido».

O responsável não é necessariamente o dono da casa, nem o que lançar a coisa ou a deixar cair. É habitante da casa, seja ele proprietário, inquilino ou ocupante a qualquer título.

Há o requisito da queda ou lançamento em lugar indevido, e, ainda uma vez, parece não haver dúvida sobre o direito de regresso contra os verdadeiros causadores do dano.

Essa matéria, no Brasil, deita fortes raízes no Direito Romano, cujo «Digesto», do Imperador Justiniano, de 530 d.C., compilou sete fragmentos a respeito, de autoria de notáveis jurisconsultos do Período Ãureo (Palus, Ulpianus e Gaius, L. IX, Tít. III, «De his, qui effuderint, vel dejicerint»).

No Código do Japão não encontramos preceito semelhante, mas não é inviável deduzí-lo dos princípios gerais, especialmente os que informam o preceito sobre danos de edifício (art. 717), com as modificações concernentes às suas peculiaridades.

\section{Regras complementares da Responsabilidade:}

1. Pluralidade da responsabilidade.

Dispõe sobre a matéria o Código do Japão:

Artigo 719. Se duas ou mais pessoas causaram por ato ilícito coletivo prejuízo a outrem, elas estão obrigadas coletiva e separadamente a fazer a compensação desse prejuízo; o mesmo se aplicará se for impossível distinguir qual dos participantes causou o prejuízo.

Instigadores e cúmplices são considerados como co-participantes.

Na versão em inglês:

Article 719. If two or more persons have by their joint unlawful act caused demage to another, they are jointly and severally liable to make compensation for such damage; 
the same shall apply if it is impossible to ascertain which of the joint participants has caused the damage.

Instigators and accomplices are deemed to be joint participants.

No Código Brasileiro, a matéria está regulada no final do caput e no parágrafo único do art. 1.518, onde se diz que os bens do responsável ficam sujeitos à reparação, e -

«se tiver mais de um autor a ofensa, todos responderão solidariamente . . » .

Além disso -

«São solidariamente responsáveis com os autores, os cúmplices e as pessoas designadas no art. 1.521».

Por outro lado, o próprio art. 1.521, no inciso $\mathrm{V}$ diz ainda que são responsáveis -

«Os que gratuitamente houverem participado do produto do crime, até à concorrente quantia».

Esclarece Bevilaqua, o autor do Projeto do Código, que este último dispositivo «não se refere a co-autores e cúmplices», mas a pessoas que não integraram a autoria do delito, embora deles, inocentemente, se tenham beneficiado, pois, assinala, «não pode ninguém locupletar-se com o alheio» (v. Código Civil Comentado», vol. V, p. 299, $6^{\text {a }}$ ed., 1947).

2. Dano ao nascituro.

O Código do Japão traz, a respeito do dano ao nascituro, uma disposição notável, que deveria servir de exemplo à legislação da generalidade dos países.

Assim se lê no art. 721:

Artigo 721. Uma criança nascitura, com respeito à reclamação de prejuízos, será considerada como se já tivesse nascido.

$\mathrm{Na}$ tradução oficial inglesa:

Article 721. A child en ventre as mere shall, in respect of his claim for damages, be deemed to have been already born.

Adota-se aí, com clareza, a assim chamada orientação concepcionista, segundo a qual o ser humano é pessoa, a partir da concepção. (V. Silmara Chivelato, «Proteção Civil do Nascituro», Tese de Doutoramento, Univ. de S. Paulo, 1983).

A posição contrária é a natalista, para a qual a pessoa só começa do nascimento com vida. 
O Código Brasileiro, na Parte Geral, art. $4^{\circ}$, segue orientação dúbia, ao determinar que -

«A personalidade civil do homem começa do nascimento com vida; mas a lei põe a salvo DESDE A CONCEPÇÃO os direitos do nascituro».

Graças a esse preceito, os juristas brasileiros se dividem entre concepcionistas e natalistas.

De nossa parte, a despeito do texto contraditório, temos sustentado que da própria disposição final resulta a personalidade a partir da concepção, pois não há possibilidade lógica de se reconhecerem direitos a um ente que não seja sujeito de direito, ao mesmo passo que não pode haver sujeito de direito que não seja considerado pessoa (v. R. Limongi França, «Manual de Direito Civil», vol. I, p. 142-145, $4^{a}$ ed., SP, RT, 1980; cf. André Franco Montoro e Anacleto de Oliveira Faria, «Condição Jurídica do Nascituro», SP, 1953)

Assim, a rigor, diante dessas normas gerais e em analogia com múltiplas normas especiais sobre os direitos do nascituro, pode-se sustentar que, no Brasil, a orientação sobre a reparação do dano ao nascituro é substancialmente a mesma do direito japonês.

\section{Estado de necessidade.}

A matéria do dano causado naquilo que, em Direito Ocidental, se denomina tecnicamente «estado de necessidade», se encontra regulada no Código do Japão, no art. 720, nestes termos:

Artigo 720. Uma pessoa que, por força da proteção do seu próprio direito ou do direito de uma terceira pessoa, contra o ato ilícito de outrem, comete inevitavelmente um ato nocivo não está obrigada ao pagamento de prejuízos; entretanto, isto não impedirá reclamação por prejuízos pela parte prejudicada contra a pessoa que cometeu o ato ilícito. As determinações do parágrafo precedente se aplicarão com as necessárias modificações aos casos em que uma coisa pertencente a outrem é danificada com o fito de impedir perigo iminente que tenha surgido dessa coisa.

A versão oficial em inglês tem este texto:

Article 720. A person who, in order to protect his own right or that of a third person against the unlawful act of another, unavoidably commits a harmful act is not liable in damages; however, this shall not preclude a claim for damages by the injured party against the person who committed the unlawful act.

The provisions of the preceding paragraph shall apply with necessary modifications to cases where a thing belonging 
to another is damaged in order to avert an imminent danger which has arisen from such thing.

Como se vê, o Código do Japão, consagra, em relação à matéria, duas espécies básicas de estado de necessidade.

$1^{\text {a }}$ Defesa contra ato ilícito de outrem.

$2^{\text {a }}$ Impedimento de perigo iminente.

Em ambas as hipóteses o causador do dano não responde, em princípio, pelos prejuízos, sendo que, no primeiro, cabe sempre reclamação contra o autor do ato ilícito.

Com relação à segunda hipótese se prevêem «necessárias modificações», sobretudo aquelas que decorrem do fato do perigo iminente não ter necessariamente sujeito responsável.

Já o Código Brasileiro, a este respeito, é bem mais complexo.

Primeiramente, é preciso assinalar que a posição sistemática da matéria é diversa, pois o assunto é regulado inicialmente na «Parte Geral» art. 160 e, ao depois, complementado no Livro das Obrigações, arts. 1.519 e 1.520 .

Em segundo lugar, há uma diferença de enfoque e de disposição.

Na Parte Geral, art. 160, começa-se por determinar que não constitui ato ilícito -

$$
\begin{aligned}
& \text { «I - Os praticados em legítima defesa ou no exercício } \\
& \text { regular de um direito. } \\
& \amalg \text { - A deterioração ou destruição da coisa alheia, a fim } \\
& \text { de remover perigo iminente. }
\end{aligned}
$$

No Livro das Obrigações, o art. 1.519 postula que, se o dono da coisa não for culpado do perigo, assistir-lhe-á direito à indenização do prejuízo sofrido, sendo que o responsável, não obstante as circunstâncias, é o autor do dano, ainda que de boa fé.

$\mathrm{O}$ art. 1.520 prevê ação regressiva em favor deste, contra terceiro eventualmente responsável.

O parágrafo único do mesmo artigo estende a norma aos casos de legítima defesa.

\section{Liquidação do dano.} assim reza:

O assunto, no Código do Japão, está previsto no art. 722 , que

Artigo 722. As determinações do art. 417 serão aplicadas com as necessárias modificações para a indenização a ser feita pelo dano causado por ato ilícito. 
Se houver culpa por parte da pessoa lesada, a Corte pode tomar isso em conta para o cálculo dos prejuízos.

$\mathrm{Na}$ versão inglesa:

Article 722. The provisions of Art. 417 shall apply with necessary modifications to the compensation to be made for the damage which has arisen from an unlawful act.

If there is any fault on the part of the injured party, the Court may take it into account in assessing the amount of the damages.

Cumpre salientar que, segundo o art. 417, na falta de acordo diverso, o montante dos prejuízos será calculado em dinheiro.

Por outro lado, parece-nos de suma importância o realce que se dá ao papel dos Tribunais, na avaliação equânime dos prejuízos, quando haja culpa também da vítima. plexa.

No Código Brasileiro, a matéria é acentuadamente mais com-

Relaciona-se com ela todo o capítulo das «Disposiçõeș Gerais» referentes à «Liquidação das Obrigações», arts. 1.533 a 1.536 , onde há preceitos minuciosos sobre vários dos seus aspectos, entre eles o do caminho do arbitramento (art. 1.536, $\S 1^{\circ}$ ) e o dos juros moratórios.

A seguir, há todo um outro capítulo especial sobre a «Liquidação das Obrigações resultantes de Atos Ilícitos».

Integram-no dezessete artigos, de 1.537 a 1.553.

A exposição respectiva, tal a complexidade, resultaria em um trabalho à parte, de modo que, a título do exemplo referiremos os artigos 1.537 a 1.548 .

O primeiro trata da indenização em caso de homicídio, a qual consiste:

I - No pagamento das despesas com o tratamento da vítima, seu funeral e o luto da família.

II - Na prestação de alimentos às pessoas a quem o defunto às devia.

Com relação a esta matéria a Jurisprudência tem aduzido alguns acréscimos, como a própria indenização por dano moral, mesmo em caso de homicídio culposo (v. R. Limongi França, "Jurisprudência de Responsabilidade Civil», p. 35-40). honra.

O outro artigo concerne à hipótese de mulher agravada em sua

Conforme o preceito, poderá exigir do ofensor, se este não puder ou não quiser reparar o dano pelo casamento, um dote correspondente à sua própria condição e estado, nos seguintes casos: 
I - Se, virgem e menor, for deflorada.

II - Se, mulher honesta, violentada ou aterrada por ameças.

III - Se foi seduzida com promessas de casamento.

\section{Prescrição.}

A prescrição da ação de responsabilidade civil, conforme o Código do Japão, assim está estabelecida no art. 724:

Artigo 724. O direito de reclamar compensação por prejuízo que tenha advindo de um alto ilícito se extinguirá por prescrição se não exercido durante três anos a contar do tempo em que a parte injuriada ou seu representante legal tenha ficado ciente de tal prejuízo e da identidade da pessoa que o causou; o mesmo se aplicará se houver escoado vinte anos a partir da data em que foi cometido o ato ilícito.

A versão oficial em inglês é esta:

Article 724. The right to claim compensation for the damage which has arisen from an unlawful act shall lapse by prescription if not exercised within three years from the time when the injured party or his legal representative became aware of such damage and of the identity of the person whon caused it; the same shall apply if twenty years have elapsed from the time when the unlawful act was committed. vinte.

Como se vê, há dois prazos diversos: um de três anos e outro de

O de três anos se conta a partir da ciência da parte prejudicada ou do seu representante quanto a dois elementos:

A) O prejuízo.

B) A identidade de quem o causou.

Se não houve tal ciência, ou se ela não abrangeu esses dois elementos, a prescrição passa a ser de vinte anos, nos claros termos do preceito.

No Código Brasileiro, a matéria de prescrição está toda unificada na Parte Geral.

Nos termos do art. 178, $\S 10$, n. IX a ação por ofensa ou dano causado ao direito de propriedade prescreve em cinco anos, "contados da data em que se deu a mesma ofensa ou dano».

Entretanto, em se tratando de prejuizos cuja natureza seja pessoal a prescrição é de vinte anos, contados da data em que a ação poderia ter sido proposta (art. 177). 


\section{B i b l i o g r a f i a}

Aussy, Charles - Le Droit Moral de l'Auteur sur les Oeuvres de Littérature \& d'Art, Paris, Pig'elet, 1911, 164 pás.

Azevedo, Filadelfo - Direito Moral do Escritor, Rio, 1930.

Chaves, Antônio - Direito Autoral de Radiofusão, S. Paulo, Ed. Rev. dos Tríbunais, 1952, págs.289-348 e 351-427.

Desbois, Henri - Le Droit d'Auteur, Paris, Dalloz, 1950, págs. 544-660.

Dozortsev, V. - Les Editeurs, les Producteurs de Phonogrammes et de Videogrammes et la Protection des Oeuvres du Domaine Public, Doc. PRS/CPY/DP/CEG LI/7, apresentado ao Comitê de Peritos Governamentais sobre a proteção das obras do domínio público, da UNESCO, reunido em Paris de 17 a 21-01-1983, 16 págs. mimeografadas.

Kruger-Nieland, Gerda - The Moral Right of the Author, a particular Manifestation of the General Personal Right, Gema New, n² 20, 1980, págs. 5-16.

Matthyssens, Jean - Le droit moral contre les fauxmonnayeurus du génie, Revue Internationale du Droit d'Auteur, no 106, 1980, págs. 3-23.

Michaélides-Nouaros, Georges - Le Droit Moral de 1'Auteur, Paris, Rousseau, 1935, 371 págs.

Mouchet, Carlos e Radaelli, Sigfrido A. - Los Derechos Del Escritor y del Artista, Madri, 1953, págs. 117-194.

Piola Caselli, Edoardo - Diritto di Autore, Nuovo Digesto Italiano, Turim, Utet, 1938 , vol. IV, págs, 1007-1013.

Plaisant, Robert - Juris Classeur de la Propriéte Littéraire et Artistique, Paris, Editions Techniques, fascículo 8, 1964, 23 págs. e fascículo 9, 1961, 30 págs. 